OPEN ACCESS

Edited by: Yi Rong,

The Ohio State University, USA

Reviewed by: Heath Brandon Mackley, Penn State Hershey Cancer Institute,

Clemens Grassberger, Harvard Medical School, USA

${ }^{*}$ Correspondence: Johnny Kao, Department of Radiation Oncology, Good Samaritan Hospital Medical Center, 1000 Montauk Highway, West Islip, NY 11795, USA johnny.kao@chsli.org

Specialty section: This article was submitted to Radiation Oncology, a section of the journal Frontiers in Oncology

Received: 27 February 2015 Accepted: 21 May 2015 Published: 23 June 2015

Citation:

Kao J, Pettit J, Zahid S, Gold KD and Palatt $T$ (2015) Esophagus and contralateral lung-sparing IMRT for locally advanced lung cancer in the community hospital setting.

Front. Oncol. 5:127.

doi: 10.3389/fonc.2015.00127

\section{Esophagus and contralateral lung-sparing IMRT for locally advanced lung cancer in the community hospital setting}

\author{
Johnny Kao ${ }^{1 *}$, Jeffrey Pettit ${ }^{1}$, Soombal Zahid ${ }^{1}$, Kenneth D. Gold ${ }^{2}$ and Terry Palatt ${ }^{3}$ \\ 'Department of Radiation Oncology, Good Samaritan Hospital Medical Center, West Islip, NY, USA, ${ }^{2}$ Division of Hematology \\ and Medical Oncology, Good Samaritan Hospital Medical Center, West Islip, NY, USA, ${ }^{3}$ Department of Surgery, Good \\ Samaritan Hospital Medical Center, West Islip, NY, USA
}

Background: The optimal technique for performing lung IMRT remains poorly defined. We hypothesize that improved dose distributions associated with normal tissue-sparing IMRT can allow safe dose escalation resulting in decreased acute and late toxicity.

Methods: We performed a retrospective analysis of 82 consecutive lung cancer patients treated with curative intent from 1/10 to 9/14. From 1/10 to 4/12, 44 patients were treated with the community standard of three-dimensional conformal radiotherapy or IMRT without specific esophagus or contralateral lung constraints (standard RT). From 5/12 to 9/14, 38 patients were treated with normal tissue-sparing IMRT with selective sparing of contralateral lung and esophagus. The study endpoints were dosimetry, toxicity, and overall survival.

Results: Despite higher mean prescribed radiation doses in the normal tissue-sparing IMRT cohort (64.5 vs. $60.8 \mathrm{~Gy}, p=0.04$ ), patients treated with normal tissue-sparing IMRT had significantly lower lung V20, V10, V5, mean lung, esophageal V60, and mean esophagus doses compared to patients treated with standard RT ( $p \leq 0.001$ ). Patients in the normal tissue-sparing IMRT group had reduced acute grade $\geq 3$ esophagitis ( 0 vs. $11 \%, p<0.001$ ), acute grade $\geq 2$ weight loss ( 2 vs. $16 \%, p=0.04$ ), and late grade $\geq 2$ pneumonitis ( 7 vs. $21 \%, p=0.02$ ). The 2 -year overall survival was $52 \%$ with normal tissue-sparing IMRT arm compared to $28 \%$ for standard RT $(p=0.015)$.

Conclusion: These data provide proof of principle that suboptimal radiation dose distributions are associated with significant acute and late lung and esophageal toxicity that may result in hospitalization or even premature mortality. Strict attention to contralateral lung and esophageal dose-volume constraints are feasible in the community hospital setting without sacrificing disease control.

Keywords: lung cancer, intensity-modulated radiation therapy, chemoradiation, toxicity, dose distribution 


\section{Introduction}

Lung cancer remains the most common cause of cancer mortality in the United States with the majority of patients presenting with locally advanced or metastatic disease (1). Patients with locally advanced and oligometastatic lung cancer are commonly treated with chemoradiation with curative intent (2-4). Lung cancer treatment planning has significantly evolved over the past two decades $(2,5)$. RTOG 94-10 used three-dimensional conformal radiotherapy limiting the spinal cord to $\leq 48$ Gy without specific lung or esophageal constraints (2). In the concurrent chemoradiation arm of RTOG 94-10, 23\% of patients developed grade $\geq 3$ esophagitis and $13 \%$ of patients developed grade $\geq 3$ pulmonary toxicity (2). As the clinical significance of volume of lung receiving $20 \mathrm{~Gy}$ and mean lung dose became established, intensity-modulated radiation therapy emerged as a potential approach to reduce lung toxicity (6, 7). In RTOG 0617, either IMRT or three-dimensional conformal radiotherapy was allowed. RTOG 0617 strongly recommended a mean lung dose $\leq 20 \mathrm{~Gy}$, volume of lung receiving $20 \mathrm{~Gy} \leq 37 \%$, and a mean esophagus dose of $<34 \mathrm{~Gy}$ (5). Despite expanded use of normal tissue constraints, $20 \%$ of patients in RTOG 0617 developed grade $\geq 3$ pulmonary toxicity. In RTOG $0617,7 \%$ of patients receiving $60 \mathrm{~Gy}$ and concurrent chemotherapy developed grade $\geq 3$ esophagitis, while $21 \%$ of patients receiving $74 \mathrm{~Gy}$ and concurrent chemotherapy developed grade $\geq 3$ esophagitis (5). Maximum grade of esophagitis predicted survival on multivariate analysis (5). Taken together, these data suggest that IMRT technique for locally advanced lung cancer requires further refinement, particularly in the community oncology setting.

Although esophageal sparing was not highly prioritized in the past, there are emerging data linking weight loss and survival in patients with lung cancer treated with chemoradiation (8). A recent analysis linked volume of esophagus receiving $60 \mathrm{~Gy}$ with esophageal toxicity (9). The MD Anderson group has demonstrated the clinical significance of sparing the contralateral lung by limiting volumes of lung receiving 5 and $10 \mathrm{~Gy}$ (10). We investigated whether IMRT designed to limit lung V20, V10, V5, mean lung dose, and esophageal dose could reduce the risk of treatment toxicity compared to historical controls treated with usual care.

\section{Materials and Methods}

\section{Patient Selection}

This retrospective study was approved by the Institutional Review Board. We reviewed 82 consecutive patients with stage II-III lung cancer, and patients with stage IV lung cancer with solitary oligometastases treated from January 2010 to September 2014. All patients had laboratory studies, computed tomography of the chest, and pathologic confirmation of malignancy. All patients had a complete metastatic workup with the vast majority of patients staged with whole body positron emission tomography and CT or MRI of the head. All patients were treated with potentially curative doses of $\geq 50$ Gy for definitive radiation or $\geq 45$ Gy in combination with surgery. Since the primary endpoints were dosimetry and toxicity rather than survival, no attempt was made to exclude patients based on histology or adjunctive treatment modalities (surgery, chemotherapy).

\section{Standard Radiation Technique}

From January 2010 to April 2012, patients were treated by four highly experienced radiation oncologists using standard planning techniques. The most common technique was three-dimensional conformal radiotherapy alone (55\%) although IMRT alone (24\%) or in combination with 3D-CRT (21\%) was also used. When IMRT was utilized, a median of five fields were used, with $33 \%$ of patients treated with seven to nine IMRT fields. During this period, the spinal cord was limited to a maximum dose of $50 \mathrm{~Gy}$, the lung V20 was generally limited to $\leq 37 \%$, and mean lung dose was $\leq 20 \mathrm{~Gy}$. Patients were treated on a Varian 21C/D linear accelerator with CT-based planning with Pinnacle using tissue inhomogeneity corrections (Philips Medical Systems, Andover, MA, USA). Patients were immobilized in the supine position using a custom Alpha Cradle mold (Alpha Cradle Molds, Akron, OH, USA). Patients treated during this interval were classified as standard RT.

\section{Normal Tissue-Sparing IMRT Technique}

From May 2012 to September 2014, all patients were treated by a single high volume radiation oncologist (J.K.) with normal tissue-sparing IMRT. A minimum of $50 \mathrm{~Gy}$ was prescribed for small cell carcinoma and a minimum of $60 \mathrm{~Gy}$ was prescribed for non-small cell lung cancer. Further dose escalation was pursued only when dose constraints were not exceeded (Table 1). The most common technique used was IMRT alone (75\%), usually a four-field technique. Patients with very bulky disease were treated with combined 3D-CRT (generally AP/PA or shallow obliques) in combination with IMRT (20\%). Two patients (5\%) with bilateral lung and/or hilar involvement, but no mediastinal involvement on PET, were treated with bilateral AP-PA fields as the optimal approach to lung and esophageal sparing.

A median of 4 IMRT fields were used with $98 \%$ of patients treated with $\leq 5$ fields. From May 2012 through January 2014, patients were treated on a Varian 21C/D with CT-based planning with PET/CT fusion. The gross tumor volume was defined as the primary tumor or any regional lymph nodes on CT $(>1 \mathrm{~cm}$ on short axis) or PET. Fusion of inhalation, expiration, and free breathing CT scans were used to assess respiratory motion and to create an ITV. After February 2014, patients were treated on the Varian TrueBeam with 4-D CT simulation using Eclipse planning. ITV to CTV margins were $0.5-1.0 \mathrm{~cm}$. CTV to PTV margins of $0.5-1 \mathrm{~cm}$ were used to create a PTV. In general, smaller margins within the range were used for bulky disease or tumor adherent to bone. When there was PET-positive disease involving the esophagus or

TABLE 1 | Normal organ constraints used for normal tissue-sparing IMRT lung plans after May 2012.

\begin{tabular}{lllll}
\hline Lungs & Esophagus & Spinal cord & Heart & $\begin{array}{l}\text { Brachial } \\
\text { plexus }\end{array}$ \\
\hline $\begin{array}{l}\text { Dmean } \\
<20 \text { Gy }\end{array}$ & Mean $<34$ Gy & Dmax $<45$ Gy & D60 $<33 \%$ & Dmax $<66$ Gy \\
V20 <37\% & $\begin{array}{l}\text { Dmax }<100 \% \text { Rx } \\
\text { (when feasible) }\end{array}$ & $\begin{array}{l}\text { Spinal canal }+ \\
5 \text { mm }<50 \text { Gy }\end{array}$ & \\
& & & D40 $<66 \%$ & \\
V10 $<50 \%$ & & & & \\
V5 $<65 \%$ & & &
\end{tabular}


vertebral bodies, the expanded PTV volumes were trimmed off critical structures to meet esophagus and spinal cord constraints.

A typical patient in the normal tissue-sparing IMRT group with a primary lung tumor with ipsilateral hilar, paratracheal, and/or aortopulmonary lymph nodes was usually treated to 64-70 Gy. When a final boost was utilized, the margins from GTV to boost PTV were limited to $1-1.2 \mathrm{~cm}$ in the superior inferior direction, $0.8-1.0 \mathrm{~cm}$ in the anterior posterior direction, and $0.5-0.8 \mathrm{~cm}$ in the medial lateral direction. Simultaneous integrated boost planning was performed to deliver radiation dose above $60 \mathrm{~Gy}$ to the bulky primary tumor and lymph nodes while administering a more conservative dose of 59.4-63 Gy to small volume CT or PET positive mediastinal lymph nodes measuring $<2 \mathrm{~cm}$ that were in close proximity to the esophagus. For patients with contralateral mediastinal or hilar adenopathy, dose escalation beyond 60 Gy was usually not technically feasible. Although elective nodal irradiation was not performed, all PET positive lymph nodes and lymph nodes measuring $>1 \mathrm{~cm}$ on short axis on CT were targeted for treatment.

\section{Follow-Up}

Patients were assessed weekly during radiation for toxicity, and weight was recorded. Following treatment, patients were reassessed at 1 month. Clinical follow-up, CT, and/or PET were performed at 3- to 4-month intervals for 2 years and at 4- to 6-month intervals thereafter. Patients were censored at last follow-up or death. Date of death was confirmed using the social security death index. Hospitalization was confirmed by reviewing the electronic medical record (EPIC).

\section{Toxicity Scoring and Statistical Methods}

Treatment-related toxicity was scored using the Common Terminology Criteria for Adverse Events version 4.0. Statistical analyses were performed on the entire cohort and for the predetermined subset of patients with stage II-III non-small cell lung cancer who were treated with definitive chemoradiation. Hospitalizations following treatment were documented in the EPIC electronic medical record. Differences in toxicity rates were assessed using a two-sided chi-square test with $p$ values of $<0.05$ considered statistically significant. Local recurrence was defined as radiographic progression within the radiation volume that was not attributed to radiation fibrosis or pneumonitis. Actuarial locoregional control and overall survival were calculated using the Kaplan-Meier method from the initiation of radiation therapy.

\section{Results}

\section{Patients and Tumor Characteristics}

Table 2 summarizes the patient and tumor characteristics for the 38 patients treated with standard technique between $1 / 10$ and 4/12 and the 44 patients treated with normal tissue-sparing IMRT between $5 / 12$ and 9/14. Median follow-up time was 14 months (range 1.4-35.3 months). Both groups were well matched in terms of age, gender, histology, smoking history, race, clinical stage, performance status, pre-treatment weight loss, tumor location, and GTV volume. The median age for all patients was 69 with $53 \%$ male, $79 \%$ non-small small cell, $83 \%$ white, $70 \%$ ECOG $0-1$, and $73 \%$ stage III. The mean GTV volume for patients receiving standard RT was 176.8 (range $13-615 \mathrm{cc}$ ) vs. 155.6 (range $4-803 \mathrm{cc}$ ) for IMRT patients $(p=0.52$ ).
TABLE 2 | Patient characteristics for patients treated with standard RT or esophagus and contralateral lung-sparing IMRT.

\begin{tabular}{|c|c|c|c|}
\hline & $\begin{array}{l}\text { Normal tissue-sparing } \\
\text { IMRT }(n=44)\end{array}$ & $\begin{array}{l}\text { Standard } \\
(n=38)\end{array}$ & $p$ \\
\hline \multicolumn{4}{|l|}{ Age (years) } \\
\hline Median & 72 & 67 & 0.63 \\
\hline Range & $30-87$ & $48-83$ & \\
\hline \multicolumn{4}{|l|}{ Gender } \\
\hline Male & 25 (56\%) & $17(45 \%)$ & 0.28 \\
\hline Female & $19(44 \%)$ & $21(55 \%)$ & \\
\hline \multicolumn{4}{|l|}{ Histology } \\
\hline Adenocarcinoma & $18(41 \%)$ & $14(37 \%)$ & 0.29 \\
\hline Squamous cell carcinoma & 15 (34\%) & 12 (32\%) & \\
\hline Small cell carcinoma & 7 (16\%) & $10(26 \%)$ & \\
\hline $\begin{array}{l}\text { Non-small cell lung } \\
\text { cancer, NOS }\end{array}$ & 4 (9\%) & 2 (5\%) & \\
\hline \multicolumn{4}{|l|}{ Smoking (pack years) } \\
\hline Never & $3(7 \%)$ & 1 (3\%) & 0.38 \\
\hline $1-20$ & 5 (11\%) & $13(34 \%)$ & \\
\hline $21-40$ & $14(37 \%)$ & 5 (13\%) & \\
\hline$>40$ & 22 (50\%) & 18 (47\%) & \\
\hline \multicolumn{4}{|l|}{ Race } \\
\hline White & 39 (89\%) & $29(76 \%)$ & 0.15 \\
\hline Non-white & $5(11 \%)$ & $9(24 \%)$ & \\
\hline \multicolumn{4}{|l|}{ Clinical stage } \\
\hline II & 7 (16\%) & $4(11 \%)$ & 0.64 \\
\hline$\| \mathrm{A}$ & $14(32 \%)$ & $19(50 \%)$ & \\
\hline IIIB & $16(36 \%)$ & $11(29 \%)$ & \\
\hline IV & 7 (16\%) & $4(11 \%)$ & \\
\hline \multicolumn{4}{|l|}{ Recurrent } \\
\hline No & 37 (84\%) & 34 (89\%) & 0.48 \\
\hline Yes & 7 (16\%) & $4(11 \%)$ & \\
\hline \multicolumn{4}{|l|}{ ECOG performance status } \\
\hline $0-1$ & 27 (61\%) & 30 (79\%) & 0.12 \\
\hline 2 & 12 (27\%) & 5 (13\%) & \\
\hline 3 & $5(11 \%)$ & $3(8 \%)$ & \\
\hline \multicolumn{4}{|l|}{ Weight loss } \\
\hline$<10 \%$ & 39 (89\%) & 34 (89\%) & 0.70 \\
\hline$>10 \%$ & $5(11 \%)$ & $4(11 \%)$ & \\
\hline \multicolumn{4}{|l|}{ Location } \\
\hline Right upper & $16(36 \%)$ & $10(26 \%)$ & 0.10 \\
\hline Right middle & $5(11 \%)$ & 3 (8\%) & (upper vs. \\
\hline Right lower & $9(20 \%)$ & 3 (8\%) & lower) \\
\hline Left upper & $9(20 \%)$ & $16(42 \%)$ & \\
\hline Left lower & $4(9 \%)$ & 5 (13\%) & \\
\hline Lymph node only & $1(2 \%)$ & $1(3 \%)$ & \\
\hline
\end{tabular}

\section{Treatment Characteristics}

Table 3 summarizes treatment parameters. Most patients were treated with concurrent chemotherapy (87\%) and without surgery (93\%). Patients in the normal tissue-sparing IMRT group received a higher mean radiation (64.5 Gy \pm SD 5.0 vs. 60.8 Gy \pm 6.2 , $p=0.04)$ and were significantly more likely to receive IMRT only compared to the standard group ( 75 vs. $24 \%, p<0.001$ ).

The normal tissue-sparing IMRT cohort had significantly lower lung V20, V10, V5, mean lung, maximum esophagus, and mean esophagus doses $(p \leq 0.001)$. Mean lung V20 was $23.3 \mathrm{~Gy} \pm \mathrm{SD}$ 7.2 in the normal tissue-sparing IMRT group vs. $32.2 \mathrm{~Gy} \pm \mathrm{SD}$ 11.6 for standard RT. Mean esophagus dose was $20.8 \mathrm{~Gy} \pm \mathrm{SD}$ 10.9 with normal tissue-sparing IMRT vs. $34.0 \mathrm{~Gy} \pm$ SD 13.7 
TABLE 3 | Treatment characteristics for patients treated with standard RT or esophagus and contralateral lung-sparing IMRT.

\begin{tabular}{|c|c|c|c|}
\hline & $\begin{array}{l}\text { Normal } \\
\text { tissue-sparing } \\
\text { IMRT }(n=44)\end{array}$ & $\begin{array}{l}\text { Standard } \\
(n=38)\end{array}$ & $p$ \\
\hline \multicolumn{4}{|l|}{ Radiation dose } \\
\hline Median & 66 & 63 & 0.04 \\
\hline$<59.4$ Gy & $6(14 \%)$ & $9(24 \%)$ & \\
\hline 59.4-63 Gy & $11(25 \%)$ & $16(32 \%)$ & \\
\hline 63.1-66 Gy & $11(25 \%)$ & $5(13 \%)$ & \\
\hline$>66.1$ Gy & 16 (36\%) & $8(21 \%)$ & \\
\hline \multicolumn{4}{|l|}{ Technique } \\
\hline IMRT only & $33(75 \%)$ & $9(24 \%)$ & $<0.001$ \\
\hline Combined & $9(20 \%)$ & $8(21 \%)$ & \\
\hline \multicolumn{4}{|l|}{ 3D-CRT + IMRT } \\
\hline 3D-CRT only & $2(5 \%)$ & $21(55 \%)$ & \\
\hline \multicolumn{4}{|l|}{ Number of IMRT fields } \\
\hline Median & 4 & 5 & 0.001 \\
\hline Range & $3-7$ & $4-9$ & \\
\hline \multicolumn{4}{|l|}{ Treatment time } \\
\hline Median & 49 & 53 & 0.31 \\
\hline Range & $37-68$ & $29-180$ & \\
\hline \multicolumn{4}{|l|}{ Chemotherapy } \\
\hline Yes & $36(82 \%)$ & $35(92 \%)$ & 0.07 \\
\hline No & $8(18 \%)$ & $3(8 \%)$ & \\
\hline \multicolumn{4}{|l|}{ Surgery } \\
\hline Yes & $4(9 \%)$ & 2 (5\%) & 0.51 \\
\hline No & 40 (91\%) & $36(95 \%)$ & \\
\hline $\begin{array}{l}\text { Lung volume } \\
\text { receiving } 20 \text { Gy }\end{array}$ & $23.3 \%(\mathrm{SD} \pm 7.2)$ & $\begin{array}{c}32.2 \% \\
(\mathrm{SD} \pm 11.6)\end{array}$ & $<0.001$ \\
\hline Range & $7-38 \%$ & $10-58 \%$ & \\
\hline $\begin{array}{l}\text { Lung volume } \\
\text { receiving } 10 \mathrm{~Gy}\end{array}$ & $33.5 \%(S D \pm 10.0)$ & $\begin{array}{c}45.7 \% \\
(\mathrm{SD} \pm 15.4)\end{array}$ & $<0.001$ \\
\hline Range & $14-52 \%$ & $15-79 \%$ & \\
\hline $\begin{array}{l}\text { Lung volume } \\
\text { receiving } 5 \text { Gy }\end{array}$ & $44.5 \%(S D \pm 13.4)$ & $\begin{array}{c}61.2 \% \\
(\mathrm{SD} \pm 18.9)\end{array}$ & $<0.001$ \\
\hline Range & $16-80 \%$ & $19-99 \%$ & \\
\hline Mean lung dose & $\begin{array}{c}14.0 \text { Gy } \\
(S D \pm 5.5 \text { Gy) }\end{array}$ & $\begin{array}{c}17.6 \text { Gy } \\
(S D \pm 5.6 \text { Gy) }\end{array}$ & 0.005 \\
\hline Range & 5.8-39.9 Gy & 5.9-26.2 Gy & \\
\hline $\begin{array}{l}\text { Maximum esophagus } \\
\text { dose } \\
\text { Range }\end{array}$ & $\begin{array}{c}56.5 \\
(\mathrm{SD} \pm 13.6 \mathrm{~Gy}) \\
\text { 6-68.3 Gy }\end{array}$ & $\begin{array}{c}61.1 \\
(\mathrm{SD} \pm 14.0 \mathrm{~Gy}) \\
45.8-70.0 \mathrm{~Gy}\end{array}$ & 0.07 \\
\hline $\begin{array}{l}\text { Mean esophagus } \\
\text { dose } \\
\text { Range }\end{array}$ & $\begin{array}{c}20.8 \text { Gy } \\
\text { (SD } \pm 10.9 \text { Gy) } \\
\text { 0.9-45.3 Gy }\end{array}$ & $\begin{array}{c}\text { 34.0 Gy } \\
\text { (SD } \pm 13.7 \text { Gy) } \\
6.8-60.1 \text { Gy }\end{array}$ & $<0.001$ \\
\hline $\begin{array}{l}\text { Esophageal volume } \\
\text { receiving } 60 \text { Gy } \\
\text { Range }\end{array}$ & 3.5 (SD \pm 5.8 Gy) & $\begin{array}{c}14.5 \\
(\mathrm{SD} \pm 16.4 \mathrm{~Gy}) \\
\text { 0-58.0 Gy }\end{array}$ & 0.001 \\
\hline Mean heart dose & $\begin{array}{c}15.2 \text { Gy } \\
(\mathrm{SD} \pm 10.4 \mathrm{~Gy})\end{array}$ & $\begin{array}{c}18.6 \text { Gy } \\
(S D \pm 9.8 \text { Gy) }\end{array}$ & 0.14 \\
\hline Range & 0.7-39.1 Gy & $0.7-34.3$ Gy & \\
\hline $\begin{array}{l}\text { Maximum spinal cord } \\
\text { dose } \\
\text { Range }\end{array}$ & $\begin{array}{c}36.2 \\
(\mathrm{SD} \pm 11.6 \mathrm{~Gy}) \\
2.1-46.5 \mathrm{~Gy}\end{array}$ & $\begin{array}{c}42.1 \\
(\mathrm{SD} \pm 9.3 \mathrm{~Gy}) \\
4.9-49.5 \mathrm{~Gy}\end{array}$ & 0.013 \\
\hline
\end{tabular}

for standard RT ( $p=0.001)$. Representative dose distributions for standard RT and normal tissue-sparing IMRT are shown in Figures 1 and 2.

\section{Acute and Late Toxicity}

The reduction in esophageal doses with normal tissue-sparing IMRT translated to significantly reduced incidence of acute grade $\geq 2$ esophagitis ( 71 vs. $31 \%, p<0.001$ ). The incidence of acute grade $\geq 3$ esophagitis was $0 \%$ with normal tissue-sparing IMRT compared to $11 \%$ with standard RT $(p<0.001)$. Average weight loss was 10.8 pounds \pm SD 10.0 for standard RT vs. 4.8 pounds \pm SD 5.6 for normal tissue-sparing IMRT $(p=0.003)$. Normal tissuesparing IMRT reduced the risk of grade $\geq 2$ weight loss ( 16 vs. $2 \%$, $p=0.04)$. There were no significant differences in acute fatigue, nausea, lung, heart, or skin toxicity between treatment groups, and grade 3 toxicities were uncommon $(<5 \%)$.

There was a significant reduction in grade $\geq 2$ radiation pneumonitis with normal tissue-sparing IMRT ( 21 vs. $7 \%, p=0.02$ ). Three patients in the standard RT group-developed grade 5 pneumonitis had lung V20 values of 41, 48, and 58\% and lung V 5 values of 90 , 99 , and $88 \%$, respectively. There was also one case of late grade 3 esophagitis and two cases of grade 3 pneumonitis with standard RT vs. none for normal tissue-sparing IMRT. The incidence of late grade $\geq 3$ pulmonary toxicity was $0 \%$ with normal tissue-sparing IMRT compared to $14 \%$ with standard RT $(p=0.02)$. The incidence of hospitalization for dehydration and/or pulmonary symptoms within 6 months of treatment was $11 \%$ for normal tissue-sparing IMRT patients vs. $37 \%$ for standard RT ( $p=0.008)$.

\section{Survival}

The 2-year overall survival was 52\% with normal tissue-sparing IMRT vs. $28 \%$ for standard RT ( $p=0.015$ ). The median survival for normal tissue IMRT was $>31$ months vs. 13 months for standard RT (Figure 3A). The 2-year locoregional control was 70\% with normal tissue-sparing IMRT vs. $42 \%$ for standard RT ( $p=0.12$ ).

\section{Patients with Stage II-III Non-Small Cell Lung Cancer Treated with Definitive Chemoradiation}

A total of 43 patients had stage II-IIIB non-small cell lung cancer that was treated with definitive chemoradiation. The patients treated with normal tissue-sparing IMRT were more likely to receive IMRT, were treated with fewer IMRT fields, and had significant reductions in lung V20, V10, V5, mean lung dose, maximum esophagus dose, mean esophagus dose, and maximum spinal cord doses. Patients treated with normal tissue-sparing IMRT had reduced rates of acute $\geq 2$ esophagitis ( 81 vs. $35 \%, p=0.001$ ), lower median weight loss ( 12.8 vs. 5.4 pounds, $p=0.01)$ and decreased late $\geq 2$ radiation pneumonitis ( 19 vs. $0 \%, p=0.04$ ). There was a trend toward decreased hospitalization for dehydration and/or pulmonary symptoms within 6 months of treatment with normal tissue-sparing IMRT (33 vs. $12 \%, p=0.12$ ). The 2 -year overall survival was $57 \%$ with normal tissue-sparing IMRT vs. $20 \%$ for standard RT $(p=0.02)$. The median survival for normal tissue IMRT was $>31$ vs. 16 months for standard RT (Figure 3B).

\section{Discussion}

IMRT has been previously shown to reduce radiation dose to normal lung translating to reduced pulmonary toxicity for patients with locally advanced lung cancer (11). Although IMRT is increasingly used in locally advanced lung cancer, a clinical advantage 


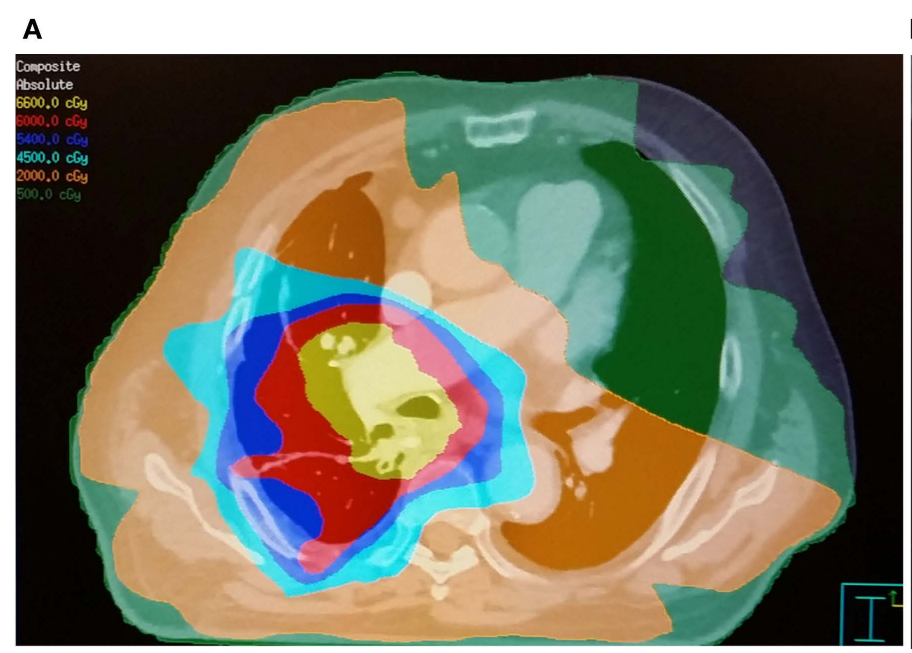

B

C
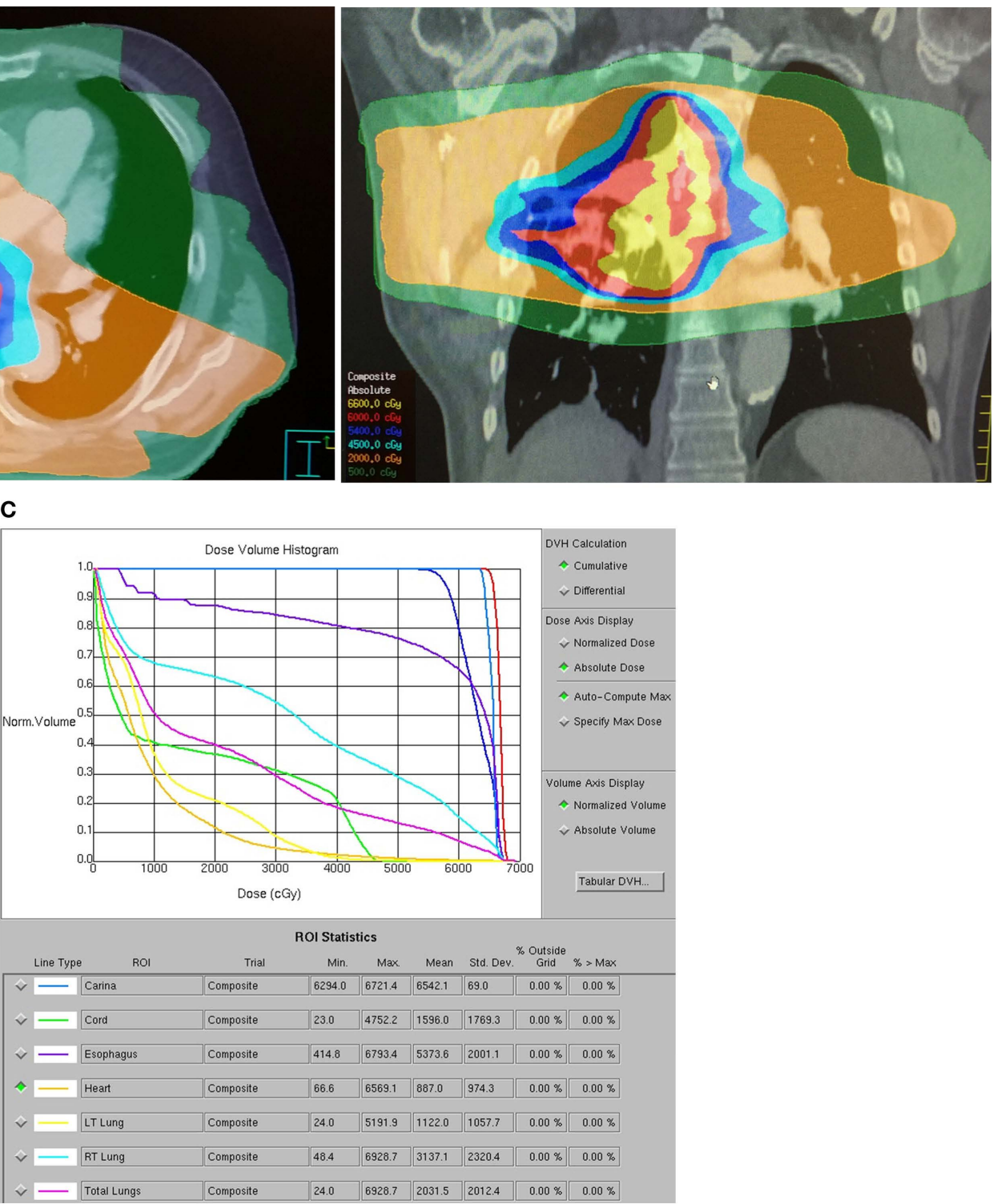

FIGURE 1 | Dose distribution for a representative patient with a $2.5 \mathrm{~cm}$ T3NOM0 stage IIB right lower lobe adenocarcinoma treated with standard RT technique. The patient was treated with carboplatin, paclitaxel, and thoracic RT to 63 Gy via six-field IMRT followed by an eight-field IMRT boost. The patient developed acute grade 2 dysphagia and grade 1 dyspnea and died 8 months after treatment from acute myocardial infarction without evidence of progression. (A) Axial dose distribution demonstrates high target volume conformality but inclusion of a significant volume of esophagus within the high dose-volume. A significant volume of lung received at least 5 Gy. (B) Coronal dose distribution. (C) Dose-volume histogram demonstrates high-esophageal V60 and high lung V5, V10, V20, and mean lung doses. over three-dimensional conformal radiotherapy remains unclear in population-based studies (12). The recently published RTOG 0617 trial allowed for IMRT for locally advanced lung cancer but a benefit for IMRT was not observed (5). As a result, some payers are reluctant to endorse IMRT for lung cancer (13). Skeptics have started to question the continuing focus on improving dose distributions in radiation oncology research (14). In terms of process improvements, expanded use of dose-volume constraints to improve outcome for patients requiring highly complex radiation treatment plans for locally advanced lung cancer could be considered analogous to use of checklists in other domains of medicine (15).
In the absence of randomized trials comparing normal tissue IMRT vs. standard RT, our study represents a natural experiment where lung cancer treatment technique abruptly transitioned from standard RT performed by four board-certified radiation oncologists to a single high volume radiation oncologist who implemented lung and esophagus-sparing IMRT (16). This study suggests that improved dose distributions resulting from adopting a policy of normal tissue-sparing IMRT favorably impacts outcome in lung cancer patients, including locally advanced non-small cell lung cancer compared to usual care by reducing high-grade lung and esophageal toxicity. The observed improvement in dosimetric 

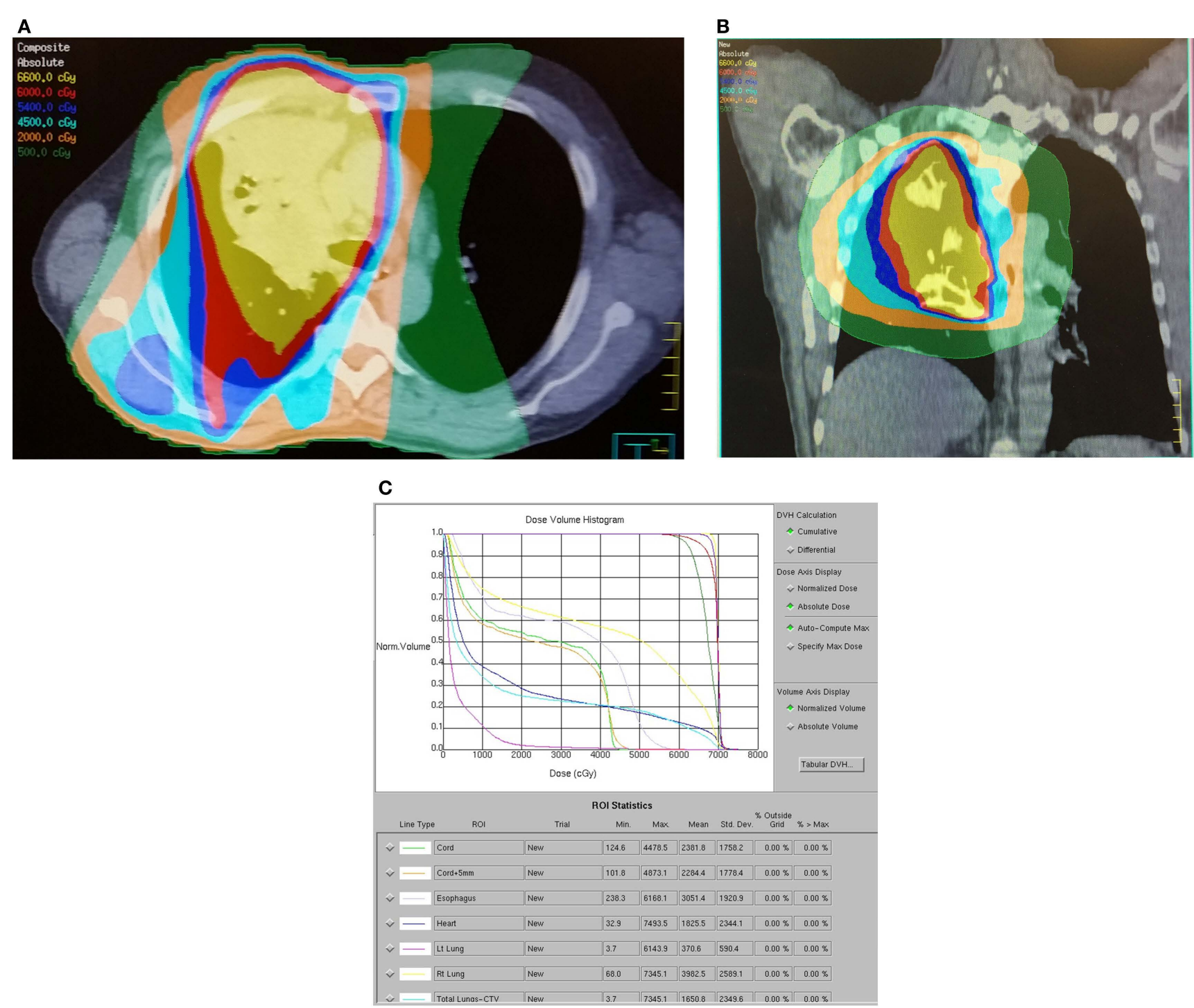

FIGURE 2 | Dose distribution for a representative patient with a $6.6 \mathrm{~cm}$ T4N2M0 stage IIIB right upper lobe adenocarcinoma treated with contralateral lung and esophageal sparing IMRT technique. The patient was treated with carboplatin, paclitaxel, and thoracic RT to 73 Gy via four-field IMRT. The patient developed acute grade 2 dysphagia, grade 1 dermatitis, and right upper arm deep vein thrombosis. The patient remains alive and free of progression or late toxicity at 21 months. (A) Axial dose distribution demonstrates relatively poor conformality but excellent sparing of the esophagus and contralateral lung. (B) Coronal isodose distribution.

(C) Dose-volume histogram demonstrates excellent coverage of the dominant mass (PTV70) and targeted lymph nodes (PTV63) with selective sparing of esophagus and lung. endpoints translated into a clinically significant reduction in hospitalization for dehydration and pulmonary complications without sacrificing disease control. Patients treated with normal tissue-sparing IMRT had improved survival compared to patients treated with standard RT. Importantly, normal tissue-sparing IMRT could be safely performed with resources available within a community hospital cancer center.

The target volumes, organs at risk, and planning techniques for locally advanced lung cancers are diverse depending on location and size of the primary tumor and extent of lymph node involvement. Although there is not yet universal agreement on the clinical relevance of lung V10 and V5, the negative impact of bilateral low-dose $(<15$ Gy) lung irradiation has been documented in diverse conditions including mesothelioma, total lung irradiation for Wilm's tumor, and total body irradiation for hematologic malignancies (17-19). The heterogeneity of IMRT planning approaches is reflected by published IMRT lung plans using between four and nine fields $(20,21)$. Typical IMRT plans utilize five or more coplanar beams that can result in up to $98 \%$ of the lung receiving 5 Gy for patients with large PTV volumes (7). Using five beams has been associated with reduced lung V 5 compared to plans using seven or nine beams (22). Recently, five- to six-field IMRT plan was associated with a higher rate of grade $\geq 3$ radiation esophagitis than three-dimensional conformal radiotherapy (23). 


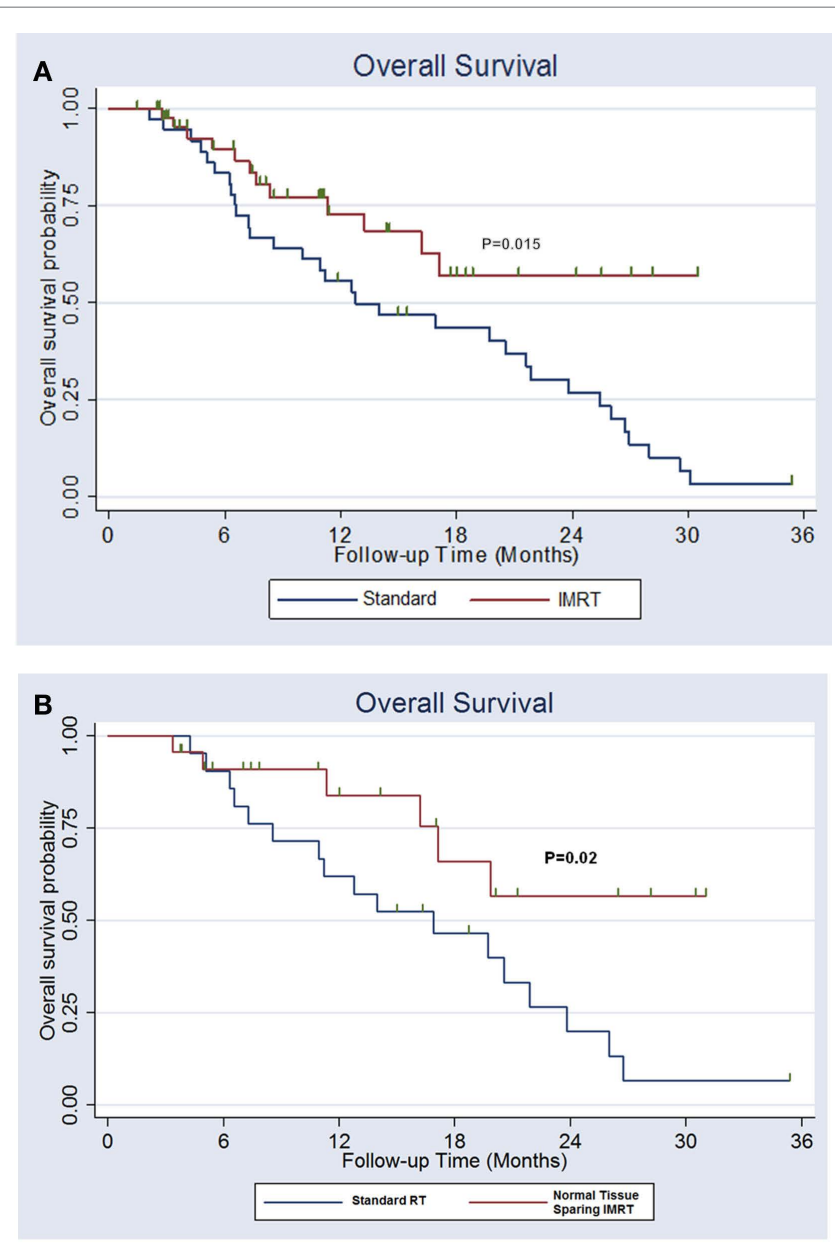

FIGURE 3 | (A) Overall survival for lung cancer patients treated with esophagus and normal lung-sparing IMRT vs. standard technique. (B) Overall survival for patients with stage II-IIIB non-small cell lung cancer receiving definitive chemoradiation treated with esophagus and normal lung-sparing IMRT vs. standard technique.

Since radiation pneumonitis is a potentially fatal complication, limiting contralateral lung exposure makes intuitive sense but is technically challenging (6). It is generally our preference to sacrifice conformality for contralateral lung avoidance by using four- to five-beam IMRT for the majority of patients. In cases where extent of disease could not be adequately covered by four- to five-IMRT fields, our preference has been to utilize limited field 3D-CRT (AP/ PA or shallow obliques) for at least part of the treatment $(24,25)$.

Esophageal sparing is controversial because mediastinal lymph nodes, especially subcarinal, posterior paratracheal, and paraesophageal lymph nodes, often overlap with the esophagus. In this study, esophageal sparing was accomplished by simply avoiding the esophagus when there was no subcarinal or paraesophageal adenopathy on PET/CT. When subcarinal or paraesophageal lymph nodes were involved, these regions were not treated above 60 Gy by constraining esophageal V60 below prescription dose.

A central conundrum in lung cancer radiotherapy is that $60 \mathrm{~Gy}$ with concurrent chemotherapy is logically inadequate for bulky disease but efforts to further escalate treatment intensity using standard radiation techniques have been unsuccessful. RTOG 0617 implies that dose escalation above $60 \mathrm{~Gy}$ with concurrent chemotherapy is counterproductive due to increased toxicity (26). A prior CALGB trial using $66 \mathrm{~Gy}$ with concurrent chemotherapy \pm induction chemotherapy resulted in poor outcomes in the cooperative group setting with survival (27). The notion that radiation dose intensification beyond 60 Gy in 6 weeks, a regimen established by RTOG 73-01, cannot be safely performed the era of IMRT, IGRT, and four-dimensional computed tomography simulation is counterintuitive $(11,28)$. Locoregional failure occurred in $31 \%$ of patients receiving 60 Gy and concurrent chemotherapy in RTOG 0617 (26). A potential solution explored in this study is administering the standard RTOG 0617 dose of 60 Gy to all areas of suspected involvement but selectively boosting bulky primary tumor and lymph nodes to 64-70 Gy. In this study, 61\% of patients in the normal tissue-sparing IMRT cohort were treated to 64-70 Gy suggesting that selective dose escalation above $60 \mathrm{~Gy}$ can safely be performed in appropriately selected patients when using strict dose-volume constraints. Stereotactic radiotherapy boost represents a similar concept but remains experimental (29).

The authors acknowledge significant weaknesses inherent in a retrospective single-institution study based in a 437-bed community teaching hospital. The sample size was small and there was significant heterogeneity of the patient population in terms of stage, histology, treatment modality, and treatment technique. When stratifying results by stage (II-III vs. IV), histology (nonsmall cell vs. small cell), and treatment modality (chemoradiation vs. radiation alone), significant reductions in lung and esophageal dosimetry, esophagitis, weight loss, and radiation pneumonitis remained statistically significant. Small cell lung cancers were included because they were treated with radiation doses and volumes similar to non-small cell lung cancers. The survival in the standard RT arm was similar to results published in CALGB 39801, which is worse than expected for a modern cohort (27). Additionally, this study did not specifically evaluate whether the observed benefit was due to IMRT, four-dimensional CT simulation, PET/CT fusion, higher radiation dose, or physician experience but instead represented two cohorts separated in time and treated by different physicians with different normal tissue constraints. Despite these limitations, this study highlights the potential importance of technique in lung cancer radiotherapy in a real-world setting.

In conclusion, these hypothesis-generating data suggest that suboptimal radiation dose distributions associated with standard technique may result in significant acute and late lung and esophageal toxicity that result in hospitalization or even premature mortality. We suggest a relatively simple four-field IMRT technique with strict attention to contralateral lung and esophageal dose-volume constraints for further validation as a potential class solution for many locally advanced lung cancers.

\section{Acknowledgments}

The authors thank Mr. Shankar Taramangalam for his assistance with data collection. 


\section{References}

1. Church TR, Black WC, Aberle DR, Berg CD, Clingan KL, Duan F, et al. Results of initial low-dose computed tomographic screening for lung cancer. $N$ Engl J Med (2013) 368(21):1980-91. doi:10.1056/NEJMoa1209120

2. Curran WJ Jr, Paulus R, Langer CJ, Komaki R, Lee JS, Hauser S, et al. Sequential vs. concurrent chemoradiation for stage III non-small cell lung cancer: randomized phase III trial RTOG 9410. JNatl Cancer Inst (2011) 103(19):1452-60. doi:10.1093/ jnci/djr325

3. Khan AJ, Mehta PS, Zusag TW, Bonomi PD, Penfield Faber L, Shott S, et al. Long term disease-free survival resulting from combined modality management of patients presenting with oligometastatic, non-small cell lung carcinoma (NSCLC). Radiother Oncol (2006) 81(2):163-7. doi:10.1016/j.radonc.2006.09.006

4. Salama JK, Vokes EE. New radiotherapy and chemoradiotherapy approaches for non-small-cell lung cancer. J Clin Oncol (2013) 31(8):1029-38. doi:10.1200/ JCO.2012.44.5064

5. Bradley JD, Paulus R, Komaki R, Masters G, Blumenschein G, Schild S, et al. Standard-dose versus high-dose conformal radiotherapy with concurrent and consolidation carboplatin plus paclitaxel with or without cetuximab for patients with stage IIIA or IIIB non-small-cell lung cancer (RTOG 0617): a randomised, two-by-two factorial phase 3 study. Lancet Oncol (2015) 16(2):187-99. doi:10.1016/ S1470-2045(14)71207-0

6. Sura S, Gupta V, Yorke E, Jackson A, Amols H, Rosenzweig KE. Intensitymodulated radiation therapy (IMRT) for inoperable non-small cell lung cancer: the Memorial Sloan-Kettering Cancer Center (MSKCC) experience. Radiother Oncol (2008) 87(1):17-23. doi:10.1016/j.radonc.2008.02.005

7. Yom SS, Liao Z, Liu HH, Tucker SL, Hu CS, WeiX, et al. Initial evaluation of treatment-related pneumonitis in advanced-stage non-small-cell lung cancer patients treated with concurrent chemotherapy and intensity-modulated radiotherapy. Int J Radiat Oncol Biol Phys (2007) 68(1):94-102. doi:10.1016/j.ijrobp.2006.12.031

8. Topkan E, Parlak C, Selek U. Impact of weight change during the course of concurrent chemoradiation therapy on outcomes in stage IIIB non-small cell lung cancer patients: retrospective analysis of 425 patients. Int J Radiat Oncol Biol Phys (2013) 87(4):697-704. doi:10.1016/j.ijrobp.2013.07.033

9. Palma DA, Senan S, Oberije C, Belderbos J, de Dios NR, Bradley JD, et al. Predicting esophagitis after chemoradiation therapy for non-small cell lung cancer: an individual patient data meta-analysis. Int J Radiat Oncol Biol Phys (2013) 87(4):690-6. doi:10.1016/j.ijrobp.2013.07.029

10. Wang S, Liao Z, Wei X, Liu HH, Tucker SL, Hu CS, et al. Analysis of clinical and dosimetric factors associated with treatment-related pneumonitis (TRP) in patients with non-small-cell lung cancer (NSCLC) treated with concurrent chemotherapy and three-dimensional conformal radiotherapy (3D-CRT). Int $J$ Radiat Oncol Biol Phys (2006) 66(5):1399-407. doi:10.1016/j.ijrobp.2006.07.1337

11. Liao ZX, Komaki RR, Thames HD Jr, Liu HH, Tucker SL, Mohan R, et al. Influence of technologic advances on outcomes in patients with unresectable, locally advanced non-small-cell lung cancer receiving concomitant chemoradiotherapy. Int J Radiat Oncol Biol Phys (2010) 76(3):775-81. doi:10.1016/j.jjrobp.2009.02.032

12. Shirvani SM, Jiang J, Gomez DR, Chang JY, Buchholz TA, Smith BD. Intensity modulated radiotherapy for stage III non-small cell lung cancer in the United States: predictors of use and association with toxicities. Lung Cancer (2013) 82(2):252-9. doi:10.1016/j.lungcan.2013.08.015

13. Bezjak A, Rumble RB, Rodrigues G, Hope A, Warde P. Intensity-modulated radiotherapy in the treatment of lung cancer. Clin Oncol (R Coll Radiol) (2012) 24(7):508-20. doi:10.1016/j.clon.2012.05.007

14. Halperin EC. The promise of innovation in radiation oncology? Lancet Oncol (2013) 14(9):802-4. doi:10.1016/S1470-2045(13)70344-9

15. Pronovost P, Needham D, Berenholtz S, Sinopoli D, Chu H, Cosgrove S, et al. An intervention to decrease catheter-related bloodstream infections in the ICU. $N$ Engl J Med (2006) 355(26):2725-32. doi:10.1056/NEJMoa061115

16. Meyer BD. Natural and Quasi-experiments in economics. J Bus Econ Stat (1995) 13:151. doi:10.1016/j.healthpol.2014.10.006
17. Allen AM, Czerminska M, Janne PA, Sugarbaker DJ, Bueno R, Harris JR, et al. Fatal pneumonitis associated with intensity-modulated radiation therapy for mesothelioma. Int J Radiat Oncol Biol Phys (2006) 65(3):640-5. doi:10.1016/j. ijrobp.2006.03.012

18. Green DM, Finklestein JZ, Tefft ME, Norkool P. Diffuse interstitial pneumonitis after pulmonary irradiation for metastatic Wilms' tumor. A report from the National Wilms' Tumor Study. Cancer (1989) 63(3):450-3.

19. Sampath S, Schultheiss TE, Wong J. Dose response and factors related to interstitial pneumonitis after bone marrow transplant. Int J Radiat Oncol Biol Phys (2005) 63(3):876-84. doi:10.1016/j.ijrobp.2005.02.032

20. Christian JA, Bedford JL, Webb S, Brada M. Comparison of inverse-planned three-dimensional conformal radiotherapy and intensity-modulated radiotherapy for non-small-cell lung cancer. Int J Radiat Oncol Biol Phys (2007) 67(3):735-41. doi:10.1016/j.ijrobp.2006.09.047

21. Stabenau H, Rivera L, Yorke E, Yang J, Lu R, Radke RJ, et al. Reduced order constrained optimization (ROCO): clinical application to lung IMRT. Med Phys (2011) 38(5):2731-41. doi:10.1118/1.3575416

22. Liu HH, Jauregui M, Zhang X, Wang X, Dong L, Mohan R. Beam angle optimization and reduction for intensity-modulated radiation therapy of non-small-cell lung cancers. Int J Radiat Oncol Biol Phys (2006) 65(2):561-72. doi:10.1016/j. ijrobp.2006.01.033

23. Gomez DR, Tucker SL, Martel MK, Mohan R, Balter PA, Lopez Guerra JL, et al. Predictors of high-grade esophagitis after definitive three-dimensional conformal therapy, intensity-modulated radiation therapy, or proton beam therapy for non-small cell lung cancer. Int J Radiat Oncol Biol Phys (2012) 84(4):1010-6. doi:10.1016/j.ijrobp.2012.01.071

24. Grills IS, Yan D, Martinez AA, Vicini FA, Wong JW, Kestin LL. Potential for reduced toxicity and dose escalation in the treatment of inoperable non-small-cell lung cancer: a comparison of intensity-modulated radiation therapy (IMRT), 3D conformal radiation, and elective nodal irradiation. Int J Radiat Oncol Biol Phys (2003) 57(3):875-90. doi:10.1016/S0360-3016(03)01359-2

25. Soyfer V, Meir Y, Corn BW, Schifter D, Gez E, Tempelhoff H, et al. AP-PA field orientation followed by IMRT reduces lung exposure in comparison to conventional 3D conformal and sole IMRT in centrally located lung tumors. Radiat Oncol (2012) 7:23. doi:10.1186/1748-717X-7-23

26. Bradley J, Paulus R, Komaki R, Masters GA, Forster K, Schild SE, et al. A randomized phase III comparison of standard-dose (60 Gy) versus high-dose (74 Gy) conformal chemoradiotherapy with or without cetuximab for stage III non-small cell lung cancer: results on radiation dose in RTOG 0617. J Clin Oncol (2013) 31(Suppl):7501.

27. Vokes EE, Herndon JE II, Kelley MJ, Cicchetti MG, Ramnath N, Neill H, et al. Induction chemotherapy followed by chemoradiotherapy compared with chemoradiotherapy alone for regionally advanced unresectable stage III Non-small-cell lung cancer: cancer and Leukemia Group B. J Clin Oncol (2007) 25(13):1698-704. doi:10.1200/JCO.2006.07.3569

28. Cox JD. Are the results of RTOG 0617 mysterious? Int J Radiat Oncol Biol Phys (2012) 82(3):1042-4. doi:10.1016/j.ijrobp.2011.12.032

29. Karam SD, Horne ZD, Hong RL, McRae D, Duhamel D, Nasr NM. Dose escalation with stereotactic body radiation therapy boost for locally advanced non small cell lung cancer. Radiat Oncol (2013) 8:179. doi:10.1186/1748-717X-8-179

Conflict of Interest Statement: The authors declare that the research was conducted in the absence of any commercial or financial relationships that could be construed as a potential conflict of interest.

Copyright (C) 2015 Kao, Pettit, Zahid, Gold and Palatt. This is an open-access article distributed under the terms of the Creative Commons Attribution License (CC BY). The use, distribution or reproduction in other forums is permitted, provided the original author(s) or licensor are credited and that the original publication in this journal is cited, in accordance with accepted academic practice. No use, distribution or reproduction is permitted which does not comply with these terms. 